www.jmscr.igmpublication.org

Impact Factor 5.84

Index Copernicus Value: 71.58

ISSN (e)-2347-176x ISSN (p) 2455-0450

crossref DOI: https://dx.doi.org/10.18535/jmscr/v6i1.99

Journal Of Medical Science And Clinical Research

\title{
Magnetic Resonance Imaging in Characterisation of Intra-Cranial Ring Enhancing Lesions in Correlation with MR Spectroscopy
}

\author{
Authors
Harshwardhan Thite ${ }^{1}$, Kulamani Sahoo ${ }^{2}$, Pramod Shaha $^{3}$, Varun Goyal ${ }^{4}$, Varun Tyagi $^{5}$ Dhruv Aggarwal ${ }^{6}$ \\ ${ }^{1,4,5,6}$ Junior Resident (Radiodiagnosis) Krishna Institute of Medical Sciences, Karad, Maharashtra. \\ ${ }^{3}$ Professor (Radiodiagnosis) Krishna Institute of Medical Sciences, Karad, Maharashtra \\ ${ }^{2}$ Professor and Head of the Dept (Radiodiagnosis) Krishna Institute of Medical Sciences, Karad, \\ Maharashtra \\ Corresponding Author \\ Harshwardhan Thite
}

Department of Radiodiagnosis, Krishna Institute of Medical Sciences, Karad, Maharashtra, India-415110

Email: harshthite22@gmail.com, Phone No- + 919881113111

\begin{abstract}
Background \& Objectives: This study is intended to study the characteristic imaging findings in various ring enhancing lesions which help in their characterization.

Methods: 50 patients (males=31; females $=19$ ) were evaluated in this study conducted at Krishna hospital \& medical research centre, Karad from Aug 2015 to Aug 2017 over a period of 2 years.

MRI along with MRS was performed using SIEMENS AVANTO $1.5 \mathrm{~T}$ in patients ranging from ages of 4-80 years.

Results: Out of the 50 patients evaluated 18 cases were tuberculomas, 12 were NCC, 5 abscesses, 10 metastasis \& amp; 5 cases of primary CNS neoplasia. Seizures were most common presenting complaint seen in 42 cases ( 84 percent). Tuberculomas were found to be most commonly occurring lesions in this part of western Maharashtra Interpretation \& Conclusion: MRI is the most sensitive modality in the characterization of intracranial ring enhancing lesions - RELs. It shows characteristic imaging findings which helps in differentiating the various RELs. MRI plays a critical role in patient management by suggesting the correct diagnosis based on characterisitic imaging findings.

Keywords: MRI; MR spectroscopy; Neurocysticercosis; tuberculoma; abscess; neoplastic.
\end{abstract}

\section{Introduction}

Multiple ring-enhancing lesions are one of the most commonly encountered neuroimaging abnormalities .Non invasive imaging techniques like computed tomography and magnetic resonance imaging (MRI) are used to detect these lesions. Ring enhancing lesions may result from a wide range of etiologies. On neuroimaging, these lesions appear as hypodense or isodense space occupying lesions on non-contrast computed (plain) tomography studies. After contrast administration, there is a ring- or a homogeneous disk-like enhancement within the region of central hypodensity. The enhancing lesions are often of variable size and are usually surrounded by a varying amount of perifocal vasogenic edema. Typically, the ring-enhancing lesions are located at the junction of the gray and white matter, but 
they could be located in the sub-cortical area, deep in the brain parenchyma or may even be superficial. Owing to MRIs high inherent soft tissue contrast and its ability to image in multiple planes MRI has a clinical advantage in early detection of disease as it can differentiate tumor , ischaemia/infarct, edema, MS plaques, infection/abscess and hemorrhage.

MR spectroscopy employs the principle of Chemical shift imaging in order to detect metabolites within a ring enhancing lesion and serves as a potential tool for differentiating between various RELs. Magnetic resonance spectroscopy (MRS) analyses the presence and/or ratio of tissue metabolites such as NAA, creatine, choline, and lactate etc.

This provides more data to understand the exact nature of the tumour and the morphological and physiological changes occurring in the surrounding brain parenchyma. Longitudinal studies have demonstrated that HMRS is useful in monitoring disease progression and treatment effects. MR spectroscopy also has a prognostic implication.

\section{Materials \& Methods \\ Source of Data}

The source of data for the study are patients from Krishna Hospital and Medical Research centre, Karad.

All patients referred to the department of Radio diagnosis with clinically suspected intra-cranial space occupying lesions in a period of 2 years from Aug 2015 to August 2017 will be subjected for the study.

\section{Inclusion Criteria}

The study include

- All cerebral ring enhancing lesions detected on contrast MR studies are taken up

- retrospectively.

- All patients with incidentally diagnosed ring enhancing lesion by $\mathrm{CT}$.

- Cases of all age groups irrespective of sex

\section{Exclusion Criteria}

The study will exclude

- Patients with head and neck trauma and Hypoxic ischemic insult

- Patient having history of metallic implants insertion, cardiac pacemakers and metallic foreign body in situ

- Patients with claustrophobia.

\section{Equipment and Technique Used}

The MRI scan was performed SIEMENS AVANTO 1.5T. It possesses a Ultra-compact, Superconducting, Active shielded superconducting magnet with a magnetic field strength of $1.5 \mathrm{~T}$.

\section{Sequences}

Conventional spin echo sequences, axial T1, T2 and FLAIR: Coronal FLAIR; Sagittal

$\mathrm{T} 1$;

Post contrast axial, coronal and sagittal,

DWI; T2 GRE

Single voxel H1 proton MR spectroscopy was performed at short TE of 35 \&amp; long TE of 144. The voxel is placed on the lesion so that it covers the enhancing wall and soft tissue component of the lesion.

We used PRESS and T1 post contrast sequence as localization sequence with $5 \mathrm{~mm}$ thickness.

Spectroscopy was avoided in small lesions close to the bone \&amp; CHESS sequence was used for water suppression.

Special sequences such as CISS 3D were used as and when required.

\section{Observations \& Results}

All observed ring enhancing lesions were thoroughly studied on various

Table No. 1: Incidence of Various Ring Enhancing Lesions

\begin{tabular}{|l|c|c|}
\hline Lesions & No. of Cases & Percentage (\%) \\
\hline Neurocysticercosis & 12 & $24 \%$ \\
\hline Tuberculoma & 18 & $36 \%$ \\
\hline Abscess & 5 & $10 \%$ \\
\hline Metastasis & 10 & $20 \%$ \\
\hline Primary neoplasms & 5 & $10 \%$ \\
\hline
\end{tabular}


Table 2

\begin{tabular}{|l|c|c|}
\hline Symptoms & No. of Cases & Percentage (\%) \\
\hline Seizures & 42 & $84 \%$ \\
\hline Headache & 11 & $22 \%$ \\
\hline Vomiting & 9 & $18 \%$ \\
\hline Weakness & 3 & $6 \%$ \\
\hline Fever & 4 & $8 \%$ \\
\hline Ataxia & 3 & $6 \%$ \\
\hline
\end{tabular}

Table No. 3

\begin{tabular}{|l|c|c|c|}
\hline Pathology & Males & Females & Total \\
\hline Tuberculoma & 12 & 6 & 18 \\
\hline NCC & 8 & 4 & 12 \\
\hline Abscess & 3 & 2 & 5 \\
\hline Metastasis & 4 & 6 & 10 \\
\hline Primary Brain Tumour & 4 & 1 & 5 \\
\hline
\end{tabular}

\section{Imaging findings in Tuberculoma}

- $88 \%$ tuberculomas appear hypointense on $\mathrm{T} 1$

- $43.7 \%$ appear hypointense on T2 while $\sim 52 \%$ appear hyperintense
- $66 . \%$ show focal restriction of diffusion

\section{Imaging findings in NCC}

- $83 \%$ appear hypointense on T1 and $100 \%$ hyperintense on $\mathrm{T} 2 \mathrm{~W}$.

- No case ( $0 \%$ ) showed restricted diffusion

Imaging finding in Metastasis:

- 50 percent appear hypointense \& 50 percent appear isointense on $\mathrm{T} 1$

- $100 \%$ appear hyperintense on T2 show focal restricted diffusion.

\section{Imaging findings in abscess}

- $100 \%$ appear hypointense on T1 \& hyperintense in $\mathrm{T} 2 \mathrm{~W}$ images

- $100 \%$ show complete restricted diffusion

\section{Imaging findings in primary neoplasia}

- All Primary malignant neoplasia shower heterogenous signal intensity and focal areas of restricted diffusion

\section{Graph No.1}

\section{Percentage occurrence of various peaks according to etiology :}

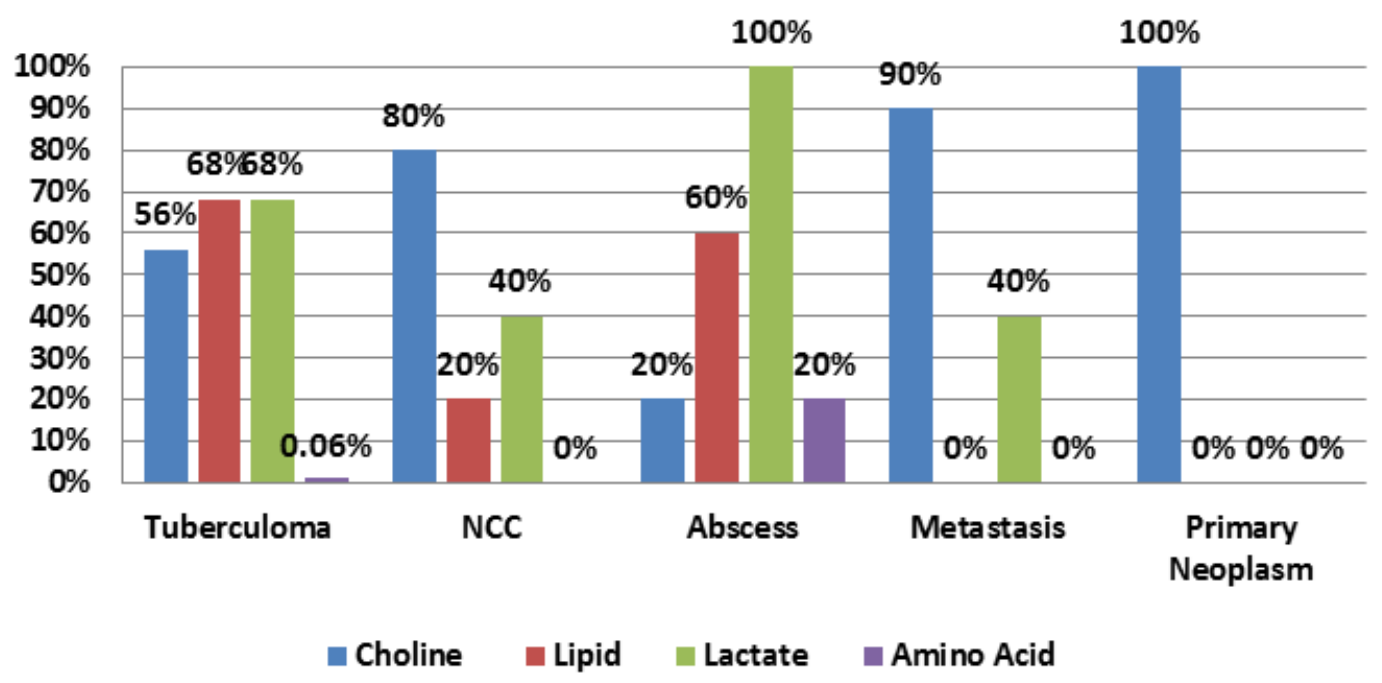

\section{Discussion}

Aprospective study was undertaken at Krishna hospital and medical research centre in order to characterize imaging findings of various ring enhancing lesions.
Magnetic resonance imaging is a non-invasive imaging modality with high inherent contrast that is sensitive to presence of a lesion. In addition to this is multi planar imaging capabilities and advanced MR sequence help in accurate localization and characterization of lesions. 
In our study of MR imaging of ring enhancing lesions of the brain, we evaluated 50 patients.

\section{Clinical Features}

Seizures are the most common presenting complaint in $84 \%$ of cases. Headache (22\%), fever (8\%), vomiting (18\%), ataxia (6\%) and motor weakness $(6 \%)$ were the other presenting complaints.

\section{Pathologies}

Out of the 50 patients who were evaluated, tuberculomas $(36 \%)$ is the most common pathology followed by NCC (24\%), metastasis $(20 \%)$, Abscesses $(10 \%)$, primary brain tumour $(10 \%)$

Tuberculoma Out of fifty patients evaluated tuberculomas were seen in $18(36 \%)$ of cases. Among the 18 cases (males $=12$ : females $=6$ ). Single lesions were noted in 6 cases $(27.2 \%)$ and multiple in 16 cases $(72.7 \%)$. They are seen as conglomerate lesions which are hypointense on both $\mathrm{T} 1$ and $\mathrm{T} 2$. On $\mathrm{T} 1$ weighted images they show a iso to hyperintense ring which was seen in 12 cases in our study. They may show partial or complete restriction seen in 13 cases $-72.2 \%$.

All our cases presented with presented with ring like enhancement. Nodular enhancement is also seen in 2 cases in addition to the ring enhancing lesions.

MRS showed a Lipid peak in $15(83.3 \%)$ cases and it plays an important role in identification of tuberculomas from other infective granulomas.

The stage of the tuberculoma whether it is caseous or non caseous can also be identified on MRI with the help of T2 weighted images. Post contrast images are very helpful in identifying the size of the tuberculomas due to its excellent spatial resolution and differentiates the granuloma from its surrounding edema.

Tae Kyoung Kim, Kee Hyun Chang, Chong Jai Kim, Jin Mo Goo, Myeong Cherl Kook, and Moon Hee Han (1995) showed that on T1weighted images, the granulomas showed a slightly hyperintense rim. On T2-weighted images, the entire portion of the granuloma showed slightly heterogeneous isointensity or hypointensity with small markedly hypointense foci. On post contrast T1-weighted images, there were single or multiple conglomerate ring enhancements within a tuberculoma in all six patients. $^{34}$

Jayasundar R, Singh VP, Raghunathan P, Jain K, Banerji AK (1999) .concluded that presence of lipid can be used for differentiating tuberculomas from both non-specific IG and NCC. ${ }^{35}$

\section{Neurocysticercosis}

Out of fifty patients evaluated neurocysticercosis was seen in 12 (males $=08$; females $=04$ ) cases. All patients presented with multiple lesions, predominantly at gray-white interface and within the sulcal spaces.

All the cases were showing intraparenchymal forms of NCC. Scolex was identified in 8 cases using CISS 3D sequence.

MRS shows Choline peak and reduced NAA peak. Gradient echo imaging played a significant role in identifying calcified lesions which were seen in 6 cases $(50.0 \%)$.

All the lesions were hypo to isointense on T1 weighted images and 12 cases were hyperintense on T2. Out of these 12 lesions 9 lesions showed inversion on FLAIR suggesting that the contents are similar to that of CSF. Intense ring enhancement with surrounding perilesional edema was seen in all cases suggestive of active lesions.

We did not find a single case of intraventricular cysticercosis probably because of the small sample of study. Martinez et al reported intraventricular neurocysticercosis in $22 \%$ of cases.

Parenchymal cysticercosis is better identified on MRI than CT in our study as compared to the study done by Suss Ra et al. ${ }^{(36)}$

Features of parenchymal forms of NCC in our study are similar to the study done by do Amaral LL et al. ${ }^{(9)}$

Cho / Cr ratio was less than 1.1 in all NCC and more than 1.2 in all tuberculoma which is similar 
to the study performed by Kumar et al and Jayasunder et al ${ }^{\text {(37 \& 38) }}$

\begin{abstract}
Abscess
Out of the 50 patients, abscess were found in 5 cases $-10 \%$ (males $=4$; females $=1$ ). Single abscess was found in 5 cases $(100 \%)$ however all the abscess showed loculations. All the cases showed sizes $>2 \mathrm{~cm}$ and one case was $>4 \mathrm{~cm}$. All were hypointense on T1 weighted images with a hyperintense rim noted in 3 patients and were hyperintense on $\mathrm{T} 2$ weighted images with a surrounding hypointense rim (5 cases). They showed complete diffusion restriction and MRS showed Lactate peak in all 5 cases suggesting anaerobic glycolysis.
\end{abstract}

Halmes et al described the appearance of abscesses on MR. We correlated our findings with those described and distinguished the peripheral oedema, central necrosis and the characteristic pattern of peripheral enhancement of the abscess capsule. $^{(39)}$

Our findings were similar to the study conducted by Tsui EY et al ${ }^{(20)}$, Shukla-Dave A et al ${ }^{(23)}$ and Leuthardt EC et al ${ }^{(18)}$.

\section{Metastasis}

Out of the 50 patients, 10 cases were metastasis (males $=3$; females $=7$ ). Multiple lesions were identified in all the five cases. All the cases showed high Cho / Cr and Cho / NAA levels. All 10 cases were hyperintense on T2 with 2 cases showing inversion on FLAIR suggestive of cystic metastasis. Primary was identified in all the women had a breast primary while the of the three men 2 had prostatic primaries and 1 had a pulmonary primary. All the patients were being treated with chemotherapy. Thick, irregular type of ring enhancement was noted after contrast administration. Findings were coherent to study conducted by Vieth et al

\section{Limitations}

$\square$ MRS could not be performed in 4 cases due to presence of lesion close to the bone. $\square$ Most of our cases $45(90 \%)$ were $<4 \mathrm{~cm}$, so single voxel spectroscopy was sufficient. But in larger lesions multivoxel spectroscopy helps in differentiating the characteristics of the internal contents as well as the wall.

\section{Conclusion}

MRI is the most sensitive and specific imaging modality for diagnosis of intracranial ring enhancing lesions.

Irregular type of ring enhancement is the most common feature noted in most of the lesions .

Most common lesion seen is Tuberculoma (36\%) followed by neurocysticercosis $(24 \%)$, abscess $(10 \%)$, metastasis $(20 \%)$, primary brain neoplasia $(10 \%)$

Ring enhancing lesions were most commonly found in $21-30$ year age group $\sim 28$ percent and most patients presented with seizures ( $84 \%$ )

In 66 percent cases ring enhancing lesions were multiple, only in 34 percent were they solitary.

Assessment of signal intensity on T2W images, DWI \& metabolite peaks of MRS helps us differentiate between benign and malignant lesion Hypointensity on T2 with evidence of restriction on DWI images and lipid peak on MRS is more in favour of Tuberculoma.

Hyperintensity on T2 with no diffusion restriction, presence of scolex on CISS 3D suggests NCC.

Abscesses show a hypointense rim on $\mathrm{T} 2$ with complete diffusion restriction. MRS may show Lactate and Amino Acids.

Metastasis are well defined hyperintense lesions on T2 which show high choline peak on MRS.

MRI plays a critical role in patient management by suggesting a narrow differential based on characteristic imaging findings

MRS helps in characterization of various ring enhancing lesions. However no lesion can be diagnosed based on the findings of MRS as the sole criteria.

\section{References}

1. Schwartz KM, Erickson BJ, Lucchinetti C Pattern of T2 hypointensity associated 
with ring-enhancing brain lesions can help to differentiate pathology Neuroradiology. 2006 Mar;48(3):143-9

2. Vasudev MK, Jayakumar PN, Srikanth SG, Nagarajan K, Mohanty A Quantitative magnetic resonance techniques in the evaluation of intracranial tuberculomas Acta Radiol. 2007 Mar;48(2):200-6.

3. Kalita J, Prasad S, Maurya PK, Kumar S, Misra UK. MR angiography in tuberculous meningitis Acta Radiol. 2012 Apr 1;53(3):324-9

4. Batra A, Tripathi RP. Diffusion-weighted magnetic resonance imaging and magnetic resonance spectroscopy in the evaluation of focal cerebral tubercular lesions. Acta Radiol. 2004 Oct;45(6):679-88

5. Gupta RK, Husain M, Vatsal DK, Kumar R, Chawla S, Husain N. Comparative evaluation of magnetization transfer MR imaging and in-vivo proton MR spectroscopy in brain tuberculomas. Magn Reson Imaging. 2002 Jun;20(5):375-81

6. Salgado $\mathrm{P}$, Del Brutto $\mathrm{OH}$, Talamás $\mathrm{O}$, Zenteno MA, Rodríguez-Carbajal J. Intracranial tuberculoma: MR imaging Neuroradiology. 1989;31(4):299-302.

7. Chang KH, Han MH, Roh JK, Kim IO, Han MC, Choi KS, Kim CW Gd-DTPA enhanced $\mathrm{MR}$ imaging in intracranial tuberculosis. Neuroradiology. 1990;32(1):19-25.

8. Daoud E, Mezghani S, Fourati H, Ketata H, Guermazi Y, Ayadi K, Dabbeche C, Mnif J, Ben Mahfoudh K, Mnif Z MR imaging features of tuberculosis of the sellar region J Radiol. 2011 Jul-Aug;92(78):714-21.

9. Amaral L, Maschietto M, Maschietto R, Cury R, Ferreira NF, Mendonça R, Lima SS. Ununsual manifestations of neurocysticercosis in MR imaging: analysis of 172 cases Arq Neuropsiquiatr. 2003 Sep;61(3A):533-41.
10. Chang KH, Han MH MRI of CNS parasitic diseases. J MagnReson Imaging. 1998 Mar-Apr;8 (2):297-307.

11. HR Martinez,R Rangel- Guerra, G Elizondo, J Gonzalez, LE Todd, J Ancer, and SS Prakash MR Imaging in neurocysticercosis: a study of 56 cases AJNR 1989; 10 (5) : 1011-1019

12. Haris M, Gupta RK, Singh A, Husain N, Husain M, Pandey CM, Srivastava C, Behari S, Rathore RK. Differentiation of infective from neoplastic brain lesions by dynamic contrast-enhanced MRI Neuroradiology. 2008 Jun;50(6):531-40 Epub 2008 Apr 1

13. Savita R Singhal, Smiti Nanda1 and Suresh K Singhal Neurocysticercosis as an important differential of seizures in pregnancy: two case reports Journal of Medical Case Reports 2011, 5:206

14. D. Pal , A. Bhattacharyya ,M. Husain ,K.N. Prasad ,C.M. Pandey ,R.K. Gupta In Vivo Proton MR Spectroscopy Evaluation of Pyogenic Brain Abscesses: A Report of 194 Cases AJNR Am J Neuroradiol Feb 2010 31:360-66

15. Mao J, Li J, Chen D, Zhang J, DU YN, Wang YJ, Li X, Wang R, Chen LY, Wang XM Value of MRI in the diagnosis of cerebral abscess caused by Candida albicans in premature infants Zhongguo Dang Dai ErKeZaZhi. 2011 Aug;13 (8):621-6.

16. G. Luthra,A. Parihar, K. Nath,S. Jaiswal,K.N. Prasad et al Comparative Evaluation of Fungal, Tubercular, and Pyogenic Brain Abscesses with Conventional and Diffusion MR Imaging and Proton MR Spectroscopy AJNR Am J Neuroradiol Aug 200728:1332-38

17. Hakyemez B, Ergin N, Uysal S, Işik I, Kiliç E Diffusion-weighted mri in the differentiation of brain abscesses and necrotic tumors Tani Girisim Radyol. 2004 Jun;10(2):110-8. 
18. Leuthardt EC, Wippold FJ 2nd, Oswood MC, Rich KM. Diffusion-weighted MR imaging in the preoperative assessment of brain abscesses. Surg Neurol. 2002 Dec;58(6):395-402;

19. Ping H. Lai, Jih T. Ho, Wei L. Chen, Shu S. Hsu, Jyh S. Wang, Huay B. Pan and Chien F. Yang Brain Abscess and Necrotic Brain Tumor: Discrimination with Proton MR Spectroscopy and Diffusion-Weighted Imaging AJNR Am J Neuroradiol 23:1369-1377, September 2002

20. Tsui EY, Chan JH, Cheung YK, Lai KF, Fong $\mathrm{D}, \mathrm{Ng} \mathrm{SH}$ Evaluation of cerebral abscesses by diffusion-weighted MR imaging and MR spectroscopy; Comput Med Imaging Graph. 2002 SepOct;26(5):347-51.

21. Fichten A, Toussaint P, Bourgeois P, Gosset JF, Lejeune JP.Diagnostic problems in brain abscess: 45 cases. Neurochirurgie. 2001 Sep;47(4):413-22

22. Kazuhiro Tsuchiya, SayukiInaoka, Yoshiyuki Mizutani, and Junichi Hachiya Fast Fluid-Attenuated Inversion-Recovery MR of Intracranial Infections AJNR Am J Neuroradiol 18:909-913, May 1997

23. Shukla-Dave A, Gupta RK, Roy R, Husain N, Paul L, Venkatesh SK, Rashid MR, Chhabra DK, Husain M Prospective evaluation of in vivo proton MR spectroscopy in differentiation of similar appearing intracranial cystic lesions. MagnReson Imaging. 2001 Jan;19(1):10310.

24. X.Z. Chen X.M. Yin L. Ai Q. Chen S.W. Li J.P. Dai Differentiation between Brain Glioblastoma Multiforme and Solitary Metastasis: Qualitative and Quantitative Analysis Based on Routine MR Imaging $\begin{array}{lll}\text { AJNR Am } & \text { J } & \text { Neuroradiol } \\ \text { 10.3174/ajnr.A3106 } & & \end{array}$

25. Sanjay K. Singh, Norman E. Leeds, and Lawrence E. Ginsberg MR Imaging of Leptomeningeal Metastases: Comparison of Three Sequences AJNR Am J Neuroradiol 23:817-821, May 2002

26. Marius Hartmann, Olav Jansen, Sabine Heiland, Clemens Sommer, Kristin Munkel, and Klaus Sartor Restricted Diffusion within Ring Enhancement Is Not Pathognomonic for Brain Abscess AJNR Am J Neuroradiol 22:1738-1742, October 2001

27. Y.M. Tang,S. Ngai,S. Stuckey The Solitary Enhancing Cerebral Lesion: Can FLAIR Aid the Differentiation between Glioma and Metastasis? AJNR Am J Neuroradiol 27:609 -11

28. C.H. Toh, K.-C. Wei,S.-H. Ng, Y.-L.Wan et al Differentiation of Brain Abscesses from Necrotic Glioblastomas and Cystic Metastatic Brain Tumors with Diffusion Tensor Imaging AJNR Am J Neuroradiol 32:1646

29. Kee-Hyun Chang, In Chan Song, Sung Hyun Kim, Moon Hee Han et al In Vivo Differentiation of Aerobic Brain Abscesses and Necrotic Glioblastomas Multiforme Using Proton MR Spectroscopic Imaging AJNR Am J Neuroradiol 29:1511-18

30. P.H. Lai, H.H. Weng C.Y, Chen S.S. Hsu et al(2008) In Vivo Differentiation of Aerobic Brain Abscesses and Necrotic Glioblastomas Multiforme Using Proton MR Spectroscopic Imaging AJNR September 2008 29: 1511-1518

31. W. Hollingworth L.S. Medina R.E. Lenkinski D.K. Shibata et al A Systematic Literature Review of Magnetic Resonance Spectroscopy for the Characterization of Brain Tumors AJNR August 2006 27: 1404-1411

32. Mishra AM, Gupta RK, Jaggi RS, et al.Role of diffusion-weighted imaging and in vivo proton magnetic resonance spectroscopy in the differential diagnosis of ring-enhancing intracranial cystic mass lesions. J Comput Assist Tomogr2004; 28:540-47 
33. Gupta RK, Prakash M, Mishra AM, et al. Role of diffusion weighted imaging in differentiation of intracranial tuberculoma and tuberculous abscess from cysticercus granulomas - a report of more than 100 lesions. Eur J Radiol2005;55:384-92

34. Tae Kyoung Kim et al Intracranial Tuberculoma: Comparison of MR with Pathologic Findings AJNR 16:1903-1908

35. Jayasundar R, Singh VP, Raghunathan P, Jain K, Banerji AK Inflammatory granulomas: evaluation with proton MRS NMR Biomed. 1999 May;12(3):139-44.

36. Suss RA, Maravilla KR, Thompson J MR imaging of intracranial cysticercosis: comparison with CT and anatomopathologic features. AJNR Am J Neuroradiol. 1986 Mar-Apr;7(2):235-42..

37. Kumar A, Kaushik S, Tripathi RP, Kaur P, Khushu S. Role of in vivo proton MR spectroscopy in the evaluation of adult brain lesions: Our preliminary experience. Neurol India 2003; 51: 474-478.

38. Gupta RK, Pandey R, Khan EM, Mittal P, Gujral RB, Chhabra DK. Intracranial tuberculomas: MRI signal intensity correlation with histopathology and localized proton spectroscopy. Magn Res Imaging 1993; 11: 443-449.

39. Halmes AB, Zimmerman RD, Morgello S, Weingarten K, Becker RD, Jennis R, Deck MD . MR Imaging of brain abscesses. AJR $1989 ; 152$ (5) : 1073-85 